\title{
Exploring the antecedents of potential absorptive capacity and its impact on innovation performance
}

\author{
Andrea Fosfuri, Josep A. Tribó* \\ Department of Business Administration, Universidad Carlos III de Madrid, C/Madrid 126, 28903 Getafe, Spain \\ Received 30 August 2005; accepted 21 June 2006 \\ Available online 15 September 2006
}

\begin{abstract}
This paper builds upon the theoretical framework developed by Zahra and George [Absorptive capacity: a review, reconceptualization, and extension. Academy of Management Review 2002;27:185-203] to empirically explore the antecedents of potential absorptive capacity (PAC), i.e. the ability to identify and assimilate external knowledge flows. Based on a sample of 2464 innovative Spanish firms, we find evidence that R\&D cooperation, external knowledge acquisition and experience with knowledge search are key antecedents of a firm's PAC. Also, during periods of important internal reshaping, when there are significant changes in strategy, design of the organization and marketing, firms exert more effort to accumulate PAC. Finally, we find that PAC is a source of competitive advantage in innovation, especially in the presence of efficient internal knowledge flows that help reduce the distance between potential and realized capacity.
\end{abstract}

Keywords: Knowledge management; Innovation; Absorptive capacity

\section{Introduction}

In a world of greater globalization and tougher competition, which is increasingly knowledge-based, firms strive to learn and to develop capabilities faster than their rivals [1]. Competitive advantages prove difficult to defend, unless they are based on dynamic capabilities that are difficult to replicate. Dynamic capabilities are embedded in organizational processes and routines, and allow a firm to quickly adapt to changing market conditions, to reconfigure its resource base, to enable

\footnotetext{
* Corresponding author. Dept. Economia de la Empresa, Univ. Carlos III, C/Madrid 126, 28903 Getafe (Madrid), Spain.

Tel.: +34916249321; fax: +34916249608.

E-mail addresses: fosfuri@emp.uc3m.es (A. Fosfuri), joatribo@emp.uc3m.es (J.A. Tribó).
}

morphing and adaptation and ultimately to achieve an edge over competitors [2].

Absorptive capacity has been recently identified as a crucial dynamic capability in knowledge-based competition [3]. In a seminal article, Cohen and Levinthal [4] defined absorptive capacity as a firm's "ability to recognize the value of new external knowledge, assimilate it and apply it to commercial ends". Given the greater availability of external knowledge sources in modern economies, a dynamic capability that influences a firm's ability to target, absorb and deploy the external knowledge necessary to feed the internal innovation process becomes a crucial source of competitive advantage. In other words, firms endowed with greater absorptive capacity are expected to outperform rivals $[5,6]$. For instance, Vekstein [7] shows that in the automobile industry the complementary use of external and internally 
developed knowledge is an important source of competitive advantage.

Although the literature on absorptive capacity has grown rich and encompasses the analyses of diverse, significant and complex organizational phenomena, only recently have some attempts been made to look deeper into the process that links external knowledge flows to firm performance. This process is moderated by a firm's absorptive capacity. In a rather influential paper, Zahra and George [3] have advanced our understanding of this process by suggesting, first, that absorptive capacity is a multidimensional construct that impinges at different times on different capabilities and routines, and, second, by pointing out to the existence of two subsets of absorptive capacity: potential and realized. Potential absorptive capacity (PAC) enables a firm's receptiveness to external knowledge; realized absorptive capacity (RAC) reflects a firm's capacity to leverage absorbed knowledge and transform it into innovation outcome. A similar characterization was advocated by Arora and Gambardella [8] who distinguished between the ability to evaluate external knowledge and the ability to exploit it, and it is also implicit in Cohen and Levinthal's [4] contribution.

This paper focuses on the first subset of absorptive capacity, PAC, and empirically explores its antecedents and its impact on innovation performance. PAC allows a firm to identify and assimilate external knowledge flows that are necessary for its innovation process. We identify as major antecedents of PAC external knowledge sources and experience with knowledge search. In addition, we investigate the moderating role of internal activation triggers (IATs), i.e. profound changes in the design of the organization, marketing and strategy. Finally, we look at the impact of PAC on innovation performance. Zahra and George [3] theorize that such impact depends on the efficiency through which PAC is transformed into RAC. We argue that, other things held equal, social integration mechanisms (SIMs) that favor the efficient circulation of information within the organization are positively associated with a firm's level of RAC.

We empirically assess these propositions using a sample of 2464 innovative Spanish firms that have answered a questionnaire about their innovation activities during the period 1998-2000. A major strength of our data set is that we have detailed information about different innovation strategies pursued by the firms, as well as information about changes in their organization, strategy and marketing designs.

We make three contributions to the literature on absorptive capacity. First, we refine the characterization of the process that links external knowledge flows to innovation performance through PAC and RAC. In this case, we build upon the theory developed by Zahra and George [3]. We conceptualize PAC as a mapping from external useful knowledge flows to internally available information. Put differently, PAC constitutes the bridge or the gate between what is outside and what is inside the organization. We view RAC as the ability to exploit this external knowledge once it has been brought within the boundaries of the organization. Second, and related, we use the theory to build a measure of PAC. Although, a better theoretical understanding of the different facets of absorptive capacity is desirable, this effort would not be fully fruitful if it cannot translate into an operationalization of the different constructs. Last, but not the least, to the best of our knowledge, we provide one of the few empirical assessments of the antecedents of PAC as well as of its effect on innovation performance. A recent notable exception is the work by Jansen et al. [9] who explore organizational mechanisms associated with coordination capabilities and organizational mechanisms associated with socialization capabilities as key drivers of PAC and RAC, respectively. They do not however empirically assess the importance of PAC for innovation performance as we do here. As Zahra and George [3] recognize, "the potential capacity component has received disproportionately less empirical scrutiny when compared with realized capacity". In this respect, the major contribution of this paper is the attempt to fill this gap.

The remainder of this paper is organized as follows. Section 2 develops the theoretical underpinnings, whereas Section 3 lays down the hypotheses to be tested. Section 4 describes our data and explains in detail the construction of our measure of PAC. In Section 5, we conduct the empirical analysis. The paper ends with some final remarks.

\section{Background theory: PAC and RAC}

Innovation is a complex activity in which new knowledge is applied to commercial ends. Part of this knowledge reaches the firm from external sources [10]. Hence, the ability to exploit external knowledge is a critical component of innovative capabilities [11]. Firms endowed with higher levels of absorptive capacity will be able to extract greater benefits from similar stocks of external knowledge, and therefore outperform rivals in their innovation activity [12]. Absorptive capacity is thus a source of competitive advantage $[3,6]$.

Recent developments in the management literature have addressed absorptive capacity as a multidimen- 
sional construct [13]. In fact, during the process of transformation of external knowledge into innovation outcomes the role played by absorptive capacity changes continuously, and absorptive capacity impinges at different times on different capabilities and routines. For instance, in their study of alliance formation in biotechnology, Arora and Gambardella [8] have distinguished between the ability to evaluate external technological information and the ability to exploit it. While the former ability is hypothesized to affect the choice of the partner of the alliance, the latter is argued to increase the value of the alliance. Kim [14] has separated the capacity to assimilate external knowledge (mostly through a process of imitation) from the ability to create new knowledge (through innovation). In his work, absorptive capacity is seen as an integral part of a learning process. Similar to the characterization we shall describe below, Zahra and George [3] have suggested distinguishing four dimensions of absorptive capacity, each playing different but complementary roles in explaining how absorptive capacity can influence innovation performance. These four dimensions are, respectively, acquisition, assimilation, transformation and exploitation. Acquisition refers to a firm's capability to identify relevant external information over the total amount of information that surrounds the firm. In other words, the firm needs to know where the sources of information are. Assimilation refers to a firm's routines and processes that allow it to analyze, process, interpret and understand the information obtained from external sources. Transformation consists of the ability to modify and adapt external knowledge and combine it with existing and internally generated knowledge. Finally, exploitation refers to the ability to transform this knowledge into competitive advantage. The first two dimensions sum up to what they label PAC. The other two dimensions constitute RAC. Whereas PAC makes a firm receptive to external knowledge flows, RAC reflects the efficiency in leveraging externally absorbed knowledge. This distinction between PAC and RAC has been recently employed by Jansen et al. [9] to investigate which organizational antecedents are associated to each of the two components of absorptive capacity.

To better capture the difference between PAC and RAC we develop below a rather stylized example that illustrates the process of transforming external knowledge into innovation outcomes. This example is useful not only to deepen the understanding of the different stages of the process, but also to theoretically motivate the measure of PAC we shall use in our empirical analysis.
Suppose a firm needs to package its current product along with a new component that would better match some specific needs of its customers (for instance, a chip-to-chip interface that enhances the technological performance of an electronic device). The firm can count both on its own internal knowledge and on external knowledge to develop the new component [10]. To simplify, let us assume that all relevant external knowledge is available through patent databases (for instance, the US Patent online database). Let $X$ be the total amount of external knowledge that would be relevant for developing the new component. The R\&D department of the firm (or some of its researchers) has to scan through the entire database to find relevant patents, i.e. patents containing useful information. ${ }^{1}$ Identifying relevant information implies first that a firm's R\&D department knows exactly where to search and how to search, and second that it is able to classify that information $[16,17]$. In order to classify the information as relevant, the R\&D department needs to understand it and ultimately assimilate it [4]. In fact, all external information the firm cannot easily comprehend is overlooked and cannot be assimilated $[18,19]$. Now, this external knowledge that has been identified and assimilated is ready to further advance in the process of transformation that leads to the development of the new component. However, how much of $X$ we are left with at this stage of the process depends on what Zahra and George [3] have labelled PAC. Hence, the larger PAC is, the larger the amount of external information that reaches this stage of the innovation process. The latter is what we define as "assimilated knowledge" (see Fig. 1).

Once this external knowledge has been brought within a firm's boundaries, it undergoes a process of transformation. The technical information available from the patents must be adapted and processed to be ready to address the specific problems the R\&D department faces in the development of the new component. During this process, knowledge is added, deleted or simply reinterpreted in a different manner. In addition, the external knowledge is integrated with internally generated knowledge. Finally, knowledge has to be turned into a tangible product. Indeed, the exploitation of knowledge is a crucial step of the innovation process. Exploitation reflects a firm's ability to harvest

\footnotetext{
${ }^{1}$ Granstrand [15] reports that, although not yet routinely exploited (except in chemicals and pharmaceuticals), patent databases are one of the most comprehensive and accessible sources of scientific and technological information. Advances in new information and communication technologies make it possible to use this rich source of data for designing technology strategies.
} 


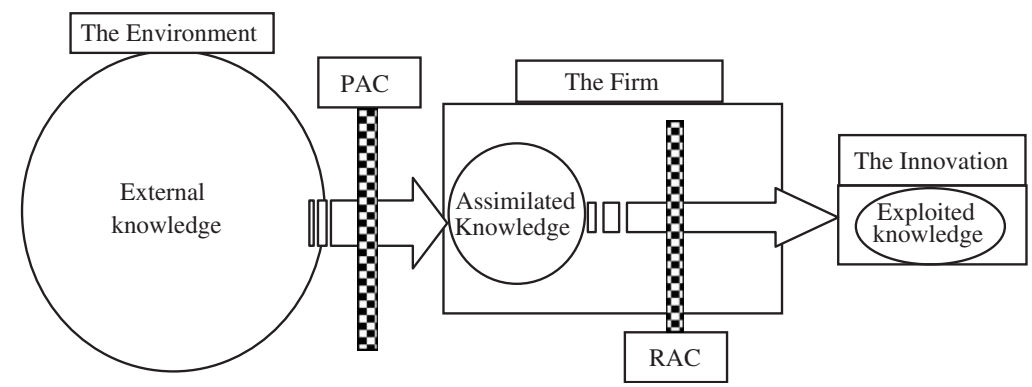

Fig. 1. From external knowledge to innovation outcomes.

and incorporate knowledge into its operations through the creation of new goods, systems, processes or organizational forms [20]. Now, how much of the external knowledge that has been brought into the organization ultimately contributes to the creation of the new component? It depends on the level of RAC. Hence, whereas PAC acts at the interface between the firm and its environment, RAC works within the organization. Zahra and George [3] use the term "efficiency factor" to refer to the relationship between PAC and RAC, where the former defines an upper limit to the role of the latter. Put differently, the efficiency factor measures the ability of the firm to create value from its knowledge base.

Fig. 1 summarizes the process of transformation of external knowledge into innovation outcomes.

\section{Hypotheses}

What are the antecedents of PAC? How do different levels of PAC affect innovation performance? In this section we address these two research questions. It is worthwhile to emphasize here that since PAC and RAC are two distinct capabilities they can potentially have different antecedents. For instance, George et al. [21] report that, in the biotechnology industry, firms with university ties are able to reduce costs and increase the number of granted patents, but not the number of products released to the market. Having more of one capability does not automatically translate in having more of the other. Thus, firms that show high levels of PAC might not ultimately enjoy superior innovation performance. While our first three hypotheses below only focus on the antecedents of PAC, the last hypothesis deals with innovation performance and must be read as contingent upon PAC. Fig. 2 presents our research model.
PAC, as many other dynamic capabilities, develops through an organization's experience-based learning [22]. As suggested by Nelson and Winter [23] much of the knowledge that permits an R\&D lab to function is tacit and, as such, it is acquired only through experience. PAC thus tends to build up cumulatively with a strong path-dependent character [4].

Zahra and George [3] identify two channels through which experiential learning helps accumulate PAC: interaction with external knowledge sources and experience with knowledge search. External knowledge sources include arms' length contracts, such as licensing, inter-firm relationships, R\&D collaborations, knowledge-driven acquisitions, etc. The greater the interaction with external knowledge sources, the larger the experiential learning accumulated by an organization in dealing with outside information. For instance, a firm that repeatedly licenses in technology or technological services from other firms develops better routines for searching and identifying new external knowledge in case it needs it. Ahuja and Katila [24] contend that when the internal and external knowledge bases contain similar elements, the knowledge identification and assimilation process is much simpler. The efficient absorption of external knowledge requires similar cognitive structures, common skills and shared languages. Thus, the experiential learning accumulated through the interaction with external knowledge sources enhances a firm's PAC. Similarly, Kumar and Nti [25] postulate that, by participating in knowledge intensive alliances, firms are able to source knowledge that enhances their competencies, among them their ability to participate in other knowledge intensive alliances. Van Wijk et al. [26] find, for instance, that the breadth and the depth of outside knowledge exposure positively influence a firm's propensity to explore new and related external knowledge. 


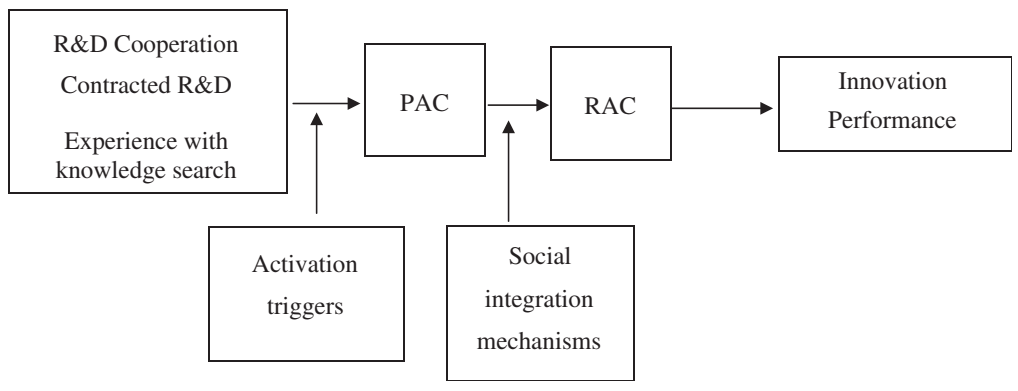

Fig. 2. Research model.

H1: Interaction with external knowledge sources, through $R \& D$ cooperation and arm's length contracted $R \& D$, has a positive impact on the level of PAC.

Experience with knowledge search is related to the experiential learning an organization has accumulated through prior innovation activity. Experience affects both the locus of search and the ability to identify and assimilate new knowledge [18]. For instance, a firm, whose R\&D employees have never published in scientific journals, may ignore the existence of specialized journals where a great deal of publicly available knowledge can be sourced. Similarly, a firm actively investigating the possibility of improving its own product can better understand the knowledge embodied in the products launched by its rivals by reverse engineering them. Organizational experience with knowledge search can also reduce uncertainty and thus increase a firm's procedural rationality [27,28], which is defined as the extent to which decision makers collect, analyze and rely upon relevant information. The outcome of greater procedural rationality is an enhanced ability to identify and assimilate external knowledge.

\section{H2: Experience with knowledge search has a positive impact on the level of PAC.}

According to Zahra and George [3] the impact of the antecedents on PAC is moderated by activation triggers. Activation triggers are defined as events that force the firm to react to given stimuli (a "shock"). Activation triggers might be internal or external. Internal triggers might be important organizational events that call for a radical change in strategy or in the design of the organization. External triggers might be due to regulatory changes, technological paradigm shifts or disruptive innovations. Kim [14] argues that discontinuous or nonlinear learning normally takes place in the presence of activation triggers. Disruptive events within the organization break existing frames, and what made sense no longer does. Hence, activation triggers might require a different type of knowledge that is not available within the firm. This feeling ignites search activities [29] and stimulates learning [30]. An activation trigger can therefore make it more attractive for a firm to expend resources in developing the capabilities to acquire and assimilate externally generated information. Activation triggers are hypothesized to induce or intensify the effort in the search for external knowledge, as well as to favor the assimilation of that knowledge as they make the firm's internal structures more flexible. Hence, activation triggers, if present, should magnify the impact of the antecedents on PAC.

\section{H3: Activation triggers positively moderate the effect of PAC antecedents.}

Many scholars have recognized that a firm's absorptive capacity is not a goal in itself, but that it moderates important organizational outcomes. For example, Cohen and Levinthal [4] relate absorptive capacity to, among others, innovative capabilities, innovation performance and expectation formation. Here, we focus specifically on how a firm's ability to first recognize external knowledge and then adapt it to its organization routines is mapped onto innovation outcomes. An important implication is that heterogeneity in the level of absorptive capacity translates into differences in the benefits from otherwise similar stocks of external knowledge. Hence, absorptive capacity is a source of competitive advantage in innovation [5,6].

Although PAC is necessary to identify and filter relevant external knowledge and capture it within the firm's boundaries, a competitive advantage in innovation only materializes if the firm also possesses RAC [3]. Indeed, the knowledge, once inside the organization, must be 
shared across the firm's members, transformed and integrated with internally generated knowledge. This process requires the existence of formal and informal mechanisms that promote knowledge transformation and exploitation. For instance, the firm can facilitate interactions across members of the organization or build knowledge/information databases that are easily accessible from everywhere in the firm. Jansen et al. [9] argue that socialization capabilities contribute to common codes of communication and dominant values. They show that socialization capabilities are positively related to RAC. Particularly, they find that the density of linkages among organization members, or connectedness, instills trust and cooperation, and facilitates the transformation and exploitation of external knowledge. Zahra and George [3] argue that RAC is only a fraction of PAC, and the magnitude of such a fraction, which they call efficiency factor, mainly depends on the presence of SIMs within the firm. Hence, two firms with the same level of PAC but different SIMs would perform differently in their innovation activity. This line of reasoning leads to the final hypothesis.

\section{H4: SIMs positively moderate the impact of PAC on innovation performance.}

\section{Data and variables}

\subsection{Data}

The data set used in this study was assembled from the 2000 Community Innovation Survey (CIS) administered in Spain in 2000 by the Spanish Institute of Statistics (INE). The purpose of the survey was to collect detailed information about innovation activities of Spanish firms belonging to all sectors of the economy during the period 1998-2000. The database is a stratified sample according to the number of employees and the sector. INE has sent the questionnaire only to firms with more than 10 employees. Firms were assigned to 55 different sectors following a Spanish classification called CNAE. ${ }^{2}$ Questionnaires were sent to the CEOs. The response rate has been quite large (92\%). This is not surprising given that Spanish firms have a legal obligation to complete the questionnaires administered by INE. The final database for the year 2000 is composed of about 16,000 firms. However, we have restricted our attention to the subsample of firms that indicated they had spent a positive amount of resources in any innova-

\footnotetext{
${ }^{2}$ In the Appendix we report the correspondence between the CNAE codes and the more standard SIC codes.
}

tion activity. In fact, the research questions we analyzed here were meaningless for those firms that did not devote resources to innovation activities. ${ }^{3}$ Also, after removing observations with missing values, we were left with a sample of 2464 firms. Some diagnostic checks have been performed to assure that the sample we employed did not suffer any serious selection bias. Specifically, we have checked that the records we removed for missing values were not different in some observable dimensions from the sample we finally used. Additionally, we have run a Heckman's two-stage selection model where in the first stage the inverse Mill ratio was obtained from a probit regression (to predict whether a firm expends resources in innovation activity) using all available observations. In the second stage, the inverse Mill ratio was included as an additional variable to explain the variation in innovation performance. These estimations, available from the authors upon request, showed that the sample selection bias was negligible for our data (i.e. the inverse Mill ratio was not significant and the coefficients of the main variables barely changed).

\subsection{Variable definition and specification}

\subsubsection{Dependent variables}

$P A C$ : This is our key variable, so we will try to be as clear as possible about its operationalization. Assume that two firms are identical in the amount of external knowledge that might be relevant to their respective innovation processes, while they differ in the levels of PAC. The former is able to identify and assimilate $80 \%$ of external potentially useful knowledge, the latter only $40 \%$. An ideal measure of PAC should be able to capture this difference.

In the questionnaire, firms rated the importance for innovation of seven external knowledge sources on a four-point scale from 1 (high) to 4 (not at all) during the period 1998-2000. Such sources are: (1) suppliers, (2) clients, (3) competitors, (4) universities, (5) other research institutions, (6) conferences, meetings and specialized journals and (7) exhibitions and showrooms. ${ }^{4}$ First, if a firm operates in a vacuum, external information would not exist and it would be classified as

\footnotetext{
${ }^{3}$ In addition, such firms are allowed to skip to fill in most parts of the questionnaire. So, we would not be able to measure key variables, like PAC.

${ }^{4}$ Firms were asked to rate the importance of each of these seven information sources either for suggesting new innovation projects or for improving existing innovation projects. Firms that had not been involved in innovation activity in the last 2 years were not asked to answer these questions.
} 
not important. Second, even when external information exists and is available, if a firm cannot identify its presence it will naturally tend to classify it as not important. Finally, to classify anything one has to have the ability to understand the object under scrutiny, assimilate it and compare it with some reference object $[15,16]$. Following this argument, we expect the answers to the questions about the importance of different information sources for innovation to depend on (a) the amount of external information available in the environment and (b) the ability of the firm to identify and assimilate it, i.e. its PAC. Moreover, the amount of external information is a function of a firm's geographical location (i.e. proximity to other firms, universities, R\&D labs, etc.) and of the sector (i.e. semiconductors is clearly different from bulk chemicals). In fact, the literature has shown that technological spillovers tend to be localized and their importance decays with distance [31].

To operationalize our measure of PAC we extracted from the importance of external knowledge flows the effect due to the sector and the geographical location. As explained above, the residual only depends on PAC plus some error. Specifically, we have proceeded as follows. First, we have built a firm-specific index that captures the importance of external knowledge flows (EXTKNOWIMP). Factor analysis was used to obtain a single factor from the aforementioned seven indicators, with a Cronbach alpha of 0.713. ${ }^{5}$ The index was then normalized to vary between 0 (not at all important) and 1 (maximum importance). Second, with such score as dependent variable, we have performed the following OLS regression: EXTKNOWIMP $=a *$ DUMMY_S + $b * \mathrm{DUMMY} \mathrm{P}+c+e$, where DUMMY_S is a vector of dummy variables for 55 sectors and DUMMY_P is a vector of dummy variables for 52 Spanish provinces, $c$ is a constant and $e$ is the error term. Finally, our measure

\footnotetext{
${ }^{5}$ We have conducted both convergent validity and discriminant validity analysis on EXTKNOWIMP. The convergent validity test is satisfied as all seven indicators show large and significant (at the 0.01 level) correlations with EXTKNOWIMP, ranging from 0.42 to 0.75 . Concerning discriminant validity, we have investigated whether these seven indicators discriminate EXTKNOWIMP from other closely related variables. We have found that the correlations are typically low (e.g. for PAC it is only 0.027), suggesting that our seven indicators are able to discriminate EXTKNOWIMP. Additionally, factor analysis indicates that the first factor only explains $37.73 \%$ of the variance and that at least five factors are needed to explain $90 \%$ of it, thereby ruling out the existence of a common method bias [32] in the measurement of EXTKNOWIMP. The Harman's singlefactor test for the existence of a common single factor explaining all seven indicators we employ for the measurement of the external spillovers was thus rejected.
}

of PAC is given by EXTKNOWIMP - a DUMMY_S b DUMMY_P, where $\mathbf{a}$ and $\mathbf{b}$ are vectors of estimated parameters.

A potential problem could arise if the error term contained in PAC was not truly an error, but instead unobserved heterogeneity. In this case, when we use PAC as a dependent variable, the covariance between the error term and the exogenous variables would be different from zero and our estimates may be biased (the problem is less serious when we use PAC as an independent variable). ${ }^{6}$ Since we have accounted for all determinants of assimilated knowledge identified by the literature, we think this problem is improbable. However, as an additional robustness check, we have estimated a regression in which we have orthogonalized our key explanatory variables (i.e. the antecedents of PAC) with respect to our measure of PAC without the white-noise error term. In this way, we have minimized the potential bias in the estimations due to the possible correlation between the non-white-noise part of the measure of PAC and the explanatory variables. The orthogonalization was obtained through the Gram-Schmidt procedure. ${ }^{7}$ As shown below (see the last column of Tables 2 and 3), results with the original and orthogonal variables are pretty similar, confirming our conjecture that in terms of the estimation such an error is truly a whitenoise.

Innovation performance: Following Cassiman and Veulegers [33] and $\mathrm{He}$ and Wong [34], innovation performance was measured as the percentage of total annual sales (by the year 2002) that consist of new or substantially improved products introduced over the period 2000-2002. The natural log of product innovation intensity has been used to compensate for skewness. As a robustness check, we estimated a probit regression using as dependent variable a dummy that equals 1 if the firm has introduced a product or a process innovation during the period 2000-2002 and 0 otherwise. Results, available from the authors upon request, hold qualitatively unchanged. See Hagedoorn and Cloodt [35] for a comparative analysis of different measures of innovation performance.

\footnotetext{
${ }^{6}$ In this case, the problem would be of multicollinearity between PAC and its determinants when all variables are introduced as regressors in the innovation performance equation. We have conducted a test of multicollinearity and the results have shown that there is no such a problem. In particular, the tolerance factor for PAC is 0.85 , for contracted $R \& D$ it is 0.87 , for $R \& D$ collaboration it is 0.81 and for experience it is 0.91 .

${ }^{7}$ The natural solution to this problem, a fixed-effect estimation, is unviable because we have only cross-sectional data.
} 
Means, standard deviations and correlations

\begin{tabular}{|c|c|c|c|c|c|c|c|c|c|c|c|c|c|c|}
\hline & Mean & S.D. & 1 & 2 & 3 & 4 & 5 & 6 & 7 & 8 & 9 & 10 & 11 & 12 \\
\hline 1 Innovation performance & 0.169 & 0.200 & 1 & & & & & & & & & & & \\
\hline 2 PAC & 1.172 & 0.074 & $0.105^{*}$ & 1 & & & & & & & & & & \\
\hline $4 \mathrm{R} \& \mathrm{D}$ collaboration & 0.268 & 0.443 & $0.067^{*}$ & $0.192^{*}$ & $0.302^{*}$ & 1 & & & & & & & & \\
\hline 5 Knowledge search experience & 0.265 & 0.659 & $0.163^{*}$ & $0.118^{*}$ & $0.117^{*}$ & $0.136^{*}$ & 1 & & & & & & & \\
\hline 6 SIMs & 0.552 & 0.497 & $0.093^{*}$ & $0.131^{*}$ & $0.085^{*}$ & $0.147^{*}$ & $0.222^{*}$ & 1 & & & & & & \\
\hline 9 Internal R\&D & 8.494 & 5.669 & $0.229^{*}$ & $0.204^{*}$ & $0.181^{*}$ & $0.278^{*}$ & $0.715^{*}$ & $0.190^{*}$ & $0.086^{*}$ & $0.191^{*}$ & 1 & & & \\
\hline 10 Size & 4.876 & 1.384 & $-0.103^{*}$ & $0.082^{*}$ & $0.159^{*}$ & $0.211^{*}$ & $0.209^{*}$ & $0.157^{*}$ & $0.081^{*}$ & $0.132 *$ & $0.076^{*}$ & 1 & & \\
\hline 11 Start-up & 0.031 & 0.172 & 0.039 & 0.008 & 0.012 & -0.019 & 0.019 & 0.026 & 0.041 & -0.045 & 0.007 & $-0.061^{*}$ & 1 & \\
\hline 12 Sector concentration $^{\mathrm{a}}$ & 32.80 & 14.711 & 0.022 & 0.000 & -0.034 & 0.025 & 0.019 & $0.064^{*}$ & $0.060^{*}$ & $-0.083^{*}$ & 0.013 & 0.037 & 0.011 & 1 \\
\hline
\end{tabular}

Note: ${ }^{*}$ Means that the correlation is significant at $1 \%$ level.

${ }^{a}$ As described in the text, we have measured sector concentration through the Herfindahl index.

\subsubsection{Explanatory variables of theoretical interest}

Contracted $R \& D$ : A specific question in the survey asked firms whether they had acquired external R\&D activity during the period 1998-2000. In the regressions we employed a dummy variable that takes the value of 1 if the firm has acquired external $R \& D$ through marketbased agreements and 0 otherwise.

$R \& D$ collaboration: A specific question in the survey asked firms whether they had undertaken R\&D collaborations with other firms or institutions during the period 1998-2000 or not. In the regressions we employed a dummy variable that takes the value of 1 if the firm has undertaken R\&D collaborations and 0 otherwise.

One may wonder whether there exists some overlapping between our measures of external knowledge sources, R\&D collaboration and contracted $R \& D$ and our measure of PAC. There is no tautology here because while PAC is obtained through a firm's subjective rating of the importance of external knowledge flows, contracted R\&D and R\&D collaboration capture a firm's objective exposure to external knowledge sources. A firm might, for instance, rate licensing agreements as an important source of external information, but have not undertaken any of such agreements. In fact, as shown in Table 1, correlations, albeit positive, are small. Moreover, as explained above, in some of the estimations we have orthogonalized contracted R\&D and R\&D collaboration with respect to our measure of PAC without the white-noise error term, thereby minimizing the risk of overlapping. ${ }^{8}$

\footnotetext{
${ }^{8} \mathrm{~A}$ related concern is the presence of multicollinearity that would suggest some redundancy in our determinants of PAC. As discussed in footnote 7 , a multicollinearity test has discarded this possibility.
}

Knowledge search experience: We measured experience with knowledge search through a firm's stock of non-expired patents. Patent stocks have been used extensively in the literature to proxy for R\&D cumulative expertise and accumulated knowledge. Among others, see George [22], Ahuja and Katila [24] and Henderson and Cockburn [36]. To control for skewness we introduced this variable in log scale.

IATs: A dummy variable that takes the value of 1 if, during the period 1998-2000, the firm has undergone a profound organizational reshaping that encompasses a change in the design of the organization, in strategy and in marketing, and 0 otherwise. In the questionnaire there are three different questions that ask for significant changes in organization, strategy and marketing, respectively. In an unreported regression, we have explored the effect of each of these changes individually. Results hold unchanged except for the fact that single changes have a smaller and less significant effect.

SIMs: There is no direct measure of SIMs in our data set. However, following the work of Jansen et al. [9] we have used the density of linkages, or connectedness, as a proxy for socialization capabilities. In the questionnaire, firms were explicitly asked to rate on a four-point scale the importance of internal information flows for innovation activity. We have focussed on information flows (1) among departments and employees and (2) among subsidiaries. We have defined a dummy variable that takes the value of 1 when the firms have identified these two sources as very important and 0 otherwise. We used this dummy multiplied by PAC to evaluate the role of SIMs as moderator of the impact of PAC on innovation performance. 


\subsubsection{Control variables}

The following variables-number of employees, export intensity, total expenditures in internal R\&D activity, industry concentration, start-up —were used as control variables. We measured the number of employees and total expenditures in internal R\&D activity in a log scale to compensate for skewness. We controlled for firm size (number of employees) because previous research has found that innovation performance might benefit from economies of scale and scope [36]. Larger firms might have also the opportunity to accumulate larger levels of PAC. The export intensity measure, defined as the total export to sales ratio, was used because a firm's innovation performance could be affected by its linkage with global markets. Total expenditures in internal $R \& D$ activity are a standard input of the $R \& D$ process, so other things held equal, one should expect this variable to have a positive impact on innovation performance (see, for instance, [36]). The related literature on absorptive capacity has also used R\&D intensity as a proxy for absorptive capacity [4]. To control for the degree of concentration in any given sector (sector concentration) we used the Herfindahl index, a standard measure in industrial economics, which indicates whether an industry is close to competition status or controlled by several large firms. Specifically, this is defined as the square root of the sum of the squares of market shares (in percentage) of all firms belonging to a given sector. The larger this variable, the more concentrated the industry is. The literature has suggested that market structure and innovation incentives are very closely related [37,38]. Finally, several authors have suggested that new ventures might have stronger incentives to innovate under certain technological regimes $[39,40]$. We therefore controlled for this possibility through a dummy variable, which takes the value of 1 if the firm is of new creation in the period 1998-2000 and 0 otherwise. New ventures start from scratch, they have almost no history, and little cumulative learning or experience. Hence, their PAC might differ substantially from that of established organizations.

In the Appendix we report some of the survey questions used to build our measures.

\section{Empirical results}

\subsection{Descriptive evidence}

Table 1 reports means, standard deviations and pairwise correlations. One can observe that there is a positive correlation (significant at the 0.01 level) between PAC and the antecedents analyzed in $\mathrm{H} 1$ and $\mathrm{H} 2$ (contracted $\mathrm{R} \& \mathrm{D}, \mathrm{R} \& \mathrm{D}$ collaboration and knowledge search experience). Also, the variable IATs is positively correlated with PAC (significant at the 0.01 level). Finally, there is a positive relationship between PAC and innovation performance as well as between our proxy for SIMs and a firm's innovation performance (significant at the 0.01 level). Hence, there is certain initial evidence that things may go in the direction we expect.

\subsection{Econometric analysis}

The stylized findings emerging from Table 1 are investigated more deeply through regression techniques. We chose both hierarchical regression and path analysis to test our hypotheses. Hierarchical regression adds controls, explanatory variables and interaction terms incrementally to gauge their relative contributions, while path analysis gives a comprehensive picture of the relative strengths of all hypothesized relationships.

Table 2 reports the results from the OLS estimation of the PAC equation. Model 1 omits the core covariates, showing only the baseline model with the control variables. Models 2 and 3 progressively add our covariates of interest. Model 4 introduces the key explanatory variables orthogonalized with respect to our measure of PAC without the white-noise error term. Variable addition increases the fit of the model, as shown by the $R^{2}$.

Empirical findings are pretty robust across all model specifications. First, the impact of external knowledge sources on the level of PAC is positive and highly significant. Having acquired external R\&D and having collaborated in $R \& D$ activities with other organizations are both important antecedents of a firm's level of PAC. This finding supports our H1. Notice that R\&D collaboration is a stronger determinant of PAC than contracted $R \& D$ is. ${ }^{9}$ This might suggest that firms accumulate more experiential learning when they have to interact with other firms rather than when they simply exchange external technological inputs through arm's length agreements. Second, the coefficient of experience with knowledge search is positive and highly significant. This implies that firms with larger stocks of non-expired patents have a higher level of PAC. This provides support to H2.

Model 3 explores the moderating role of IATs. The theory developed by Zahra and George [3] suggests that

\footnotetext{
${ }^{9}$ We have conducted two parameter tests under the null hypothesis of equal value of the coefficients of $R \& D$ collaboration and contracted R\&D and R\&D collaboration and knowledge search experience, respectively. The null hypothesis has been rejected in both cases $(p$-value $=0.077$ for the former and 0.029 for the latter).
} 


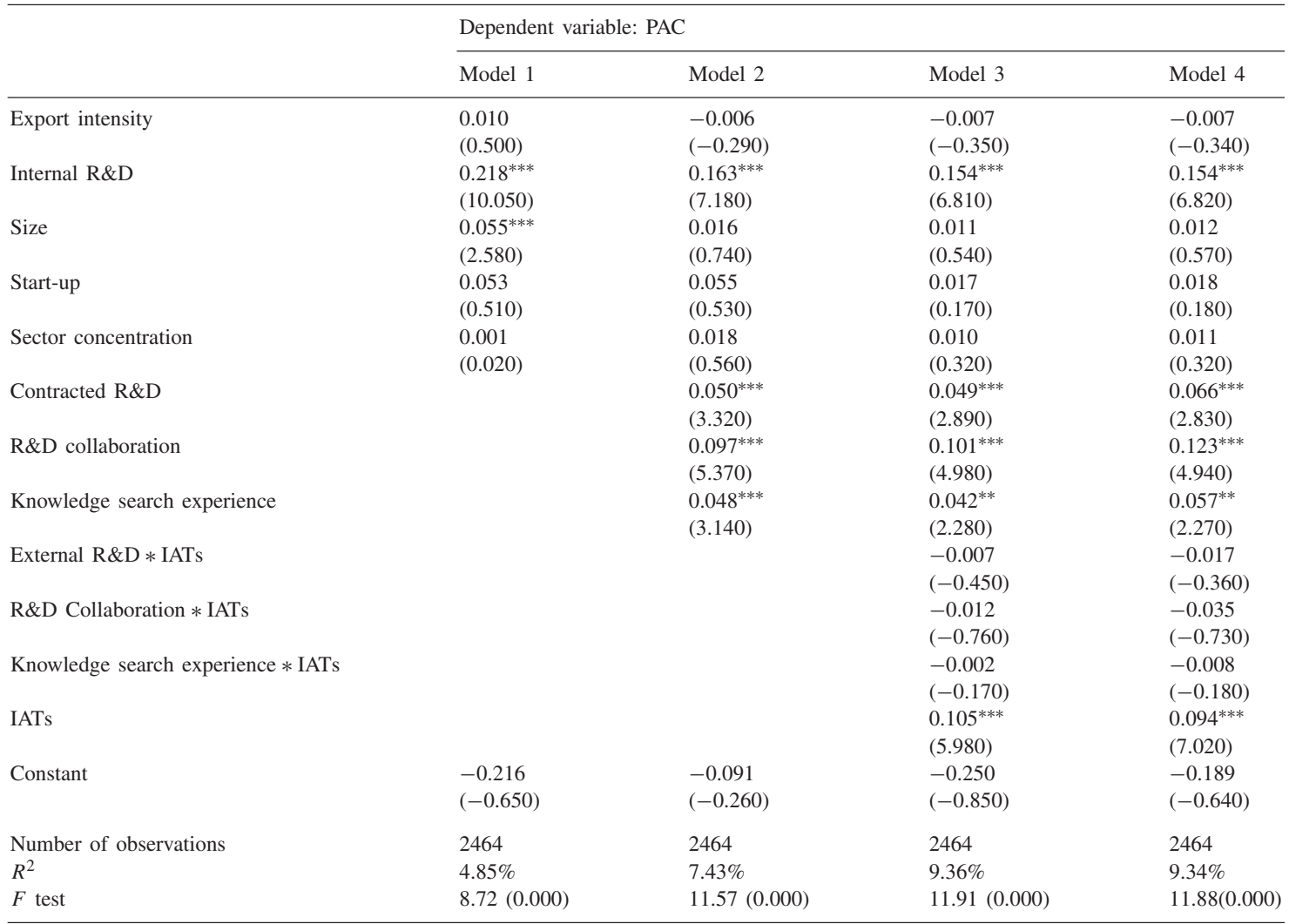

Note: ${ }^{* * *} p$-value $0.01,{ }^{* *} p$-value $0.05,{ }^{*} p$-value 0.10 ( $p$-value in parentheses). See the definition of the variables in the text. In model 4 , we have orthogonalized the variables contracted $R \& D, R \& D$ collaboration and knowledge search experience as described in the text.

in the presence of IATs, the role of some crucial antecedents of PAC is magnified. To capture this effect we constructed three additional variables that are the product of our three antecedents of PAC times IATs. Model 3 also includes IATs as an additional regressor. We have not found empirical support for Hypothesis 3. In fact, all interaction variables show insignificant coefficients, although the coefficient for IATs is positive and highly significant. This finding seems to suggest that IATs do not act as moderating mechanisms, although they directly contribute to the accumulation of PAC. Finally, as model 4 shows, qualitatively results hold unchanged when we orthogonalize the main explanatory variables with respect to our measure of PAC without the white-noise component of the error term. This finding confirms that, in terms of the estimation, the error term contained in the measure of PAC is truly a white-noise.

Finally, concerning the other control variables we only find a significant and positive sign for the log of total expenditures in internal R\&D activity. This implies that firms with a larger amount of resources dedicated to internal R\&D tend to show higher levels of PAC. This finding is consistent with the story of the "double face of R\&D” as initially told by Cohen and Levinthal [41], i.e. $R \& D$ efforts increase both innovation performance and absorptive capacity. Controls for firms' size, startups, export intensity and industry concentration do not show any significant effect in determining a firm's PAC.

Table 3 addresses the impact of PAC on innovation performance as discussed in H4. Model 1 omits the core covariates, showing only the baseline model with the control variables, while models $2-5$ progressively add the covariates of interest. First, notice that in all model specifications PAC shows a positive and highly significant coefficient. For instance, using model 3 and holding all other variables at their median values, an increase in PAC from its median value to the upper quartile of the distribution raises the share of sales due to new or 
Table 3

The impact of PAC on innovation performance (OLS regressions)

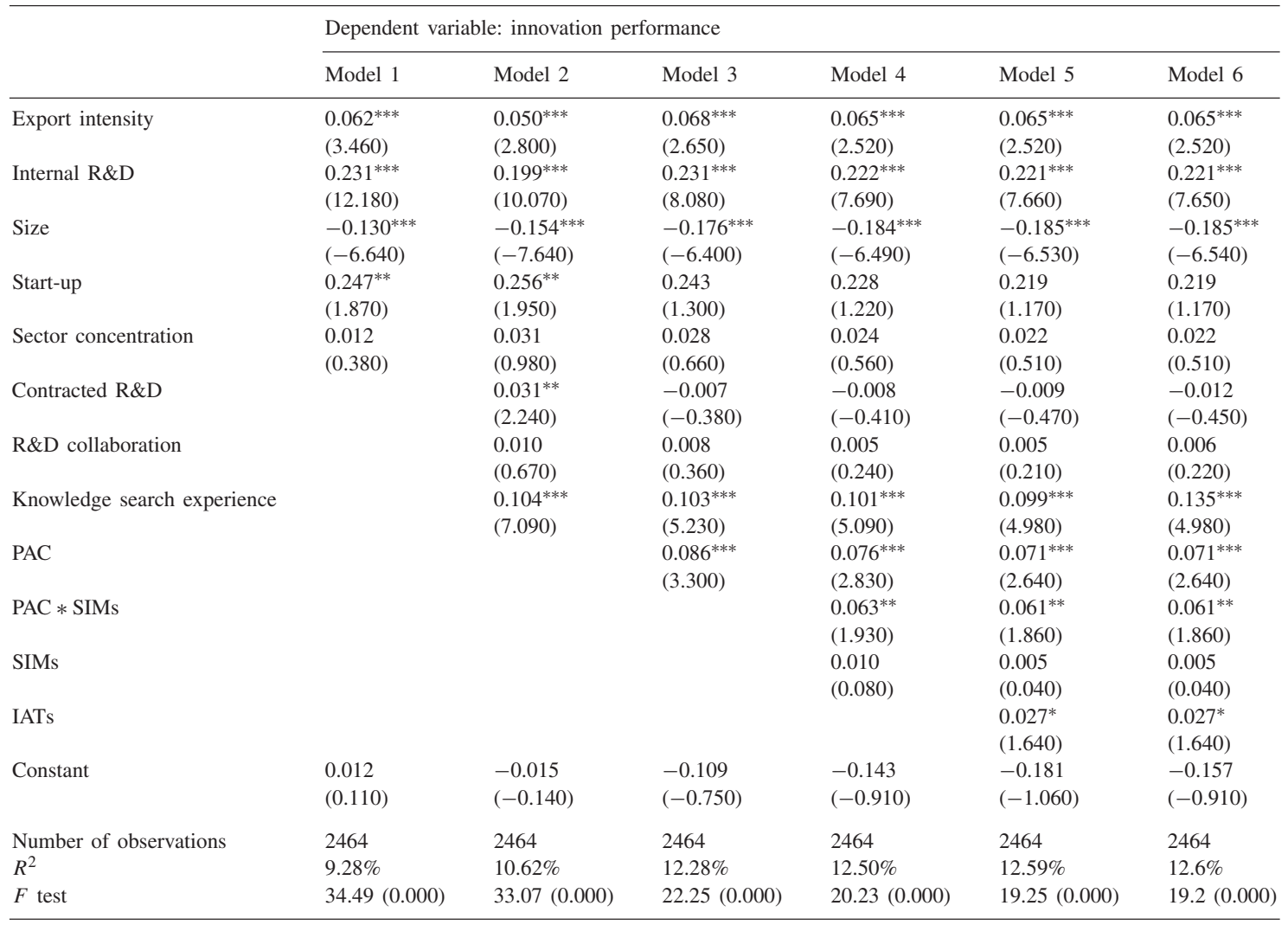

Note: ${ }^{* * *} p$-value $0.01,{ }^{* *} p$-value $0.05,{ }^{*} p$-value 0.10 ( $p$-values in parentheses). See the definition of the variables in the text. In model 6 , we have orthogonalized the variables contracted $R \& D, R \& D$ collaboration and knowledge search experience as described in the text.

substantially improved products from $8.78 \%$ to $9.68 \%$. Second, model 4 shows that the role of PAC as a source of competitive advantage in innovation is greater in the presence of SIMs. Indeed, the interaction term between PAC and SIMs, which should capture the moderating role, has a positive and significant effect. PAC is therefore more important when information can be easily shared across different members of the organization. In Fig. 3, using model 5 and holding all other variables at their median values, we plot the relationship between innovation performance and PAC for SIMs $=0$ and 1 (internal sources of knowledge moves from non-important to very important). This figure shows that when SIMs change from 0 to 1 the line that draws the relationship between innovation performance and PAC both shifts upwards and becomes steeper (its slope increases from 0.146 to 0.162 ). Hence, for a given level of PAC, the

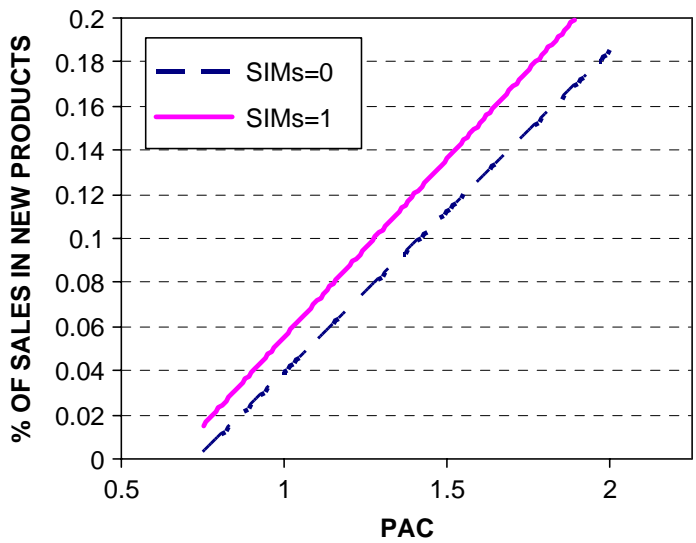

Fig. 3. Effect of the interaction between PAC and SIMs on innovation performance. 


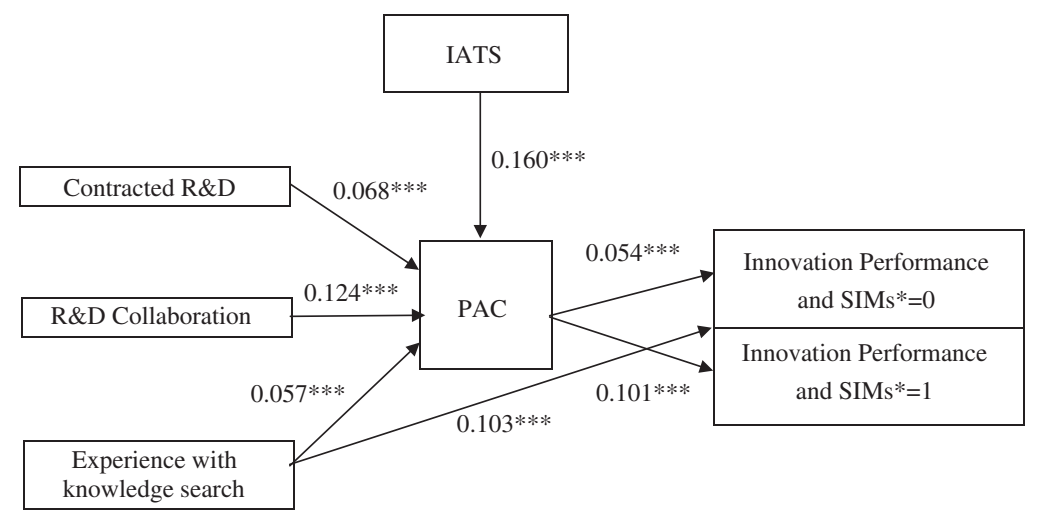

Fig. 4. Standardized parameter estimates for path analysis.

difference in innovation performance across firms is due to differences in their respective efficiency factors [3].

Model 5 also includes as control variables our antecedents of PAC and the variable IATs. Interesting enough, these variables, except for experience with knowledge search, have an insignificant effect on innovation performance. So, their impact on innovation performance is basically channelled through a firm's absorptive capacity. Finally, model 6 employs the orthogonalized values of the antecedents of PAC. Results are similar to those obtained in model 5 .

Other control variables have a plausible sign. Total expenditures in internal $R \& D$ have a positive and significant effect on innovation performance. Firms with greater exposure to international markets perform better in innovation activity (i.e. export intensity shows a positive sign). Larger firms seem to have a disadvantage vis-à-vis smaller firms, confirming that more flexible, smaller organizations are better suited for innovation activity. However, the effect seems to be due to size and not to the age of the organization. Indeed, new ventures do not show any significant advantage. Finally, the degree of concentration in the industry does not show a significant effect.

As robustness, we have used path analysis techniques to estimate our model. Fig. 4 shows the results of such analysis.

To be consistent with the previous estimations we have used the generalized least square (GLS) approach instead of MLE techniques (pathreg instruction of STATA package). The overall model-in the figure we do not show control variables-is fully significant as its $\chi^{2} / D F=0.103$ is well below 3, the threshold that is considered acceptable in the literature (see [42]). Moreover the $F$ test is also significant as $F(20,2464)=12.5802$ with Prob $>F=0.000$. Finally, the likelihood ratio test has a $p$-value $=242.068$ and it is significant at the 0.01 level.

The results are similar to earlier regression results. First, the aforementioned antecedents (contracted R\&D, R\&D collaboration and knowledge search experience) are significant at the 0.01 level as antecedents of a firm's level of PAC. Second, PAC has a significant positive impact on innovation performance, especially in those firms with efficient internal information flows. Indeed, the estimated coefficient moves from 0.054 when $\mathrm{SIMs}=0$ to 0.101 when $\mathrm{SIMs}=1$.

\section{Conclusions and discussion}

The baseline assumption in this paper is that absorptive capacity is a multidimensional construct. In the process of transformation of external knowledge flows into innovation outcomes, the role played by absorptive capacity changes continuously, and absorptive capacity impinges at different times on different capabilities and routines. Specifically, we have focussed our attention on the ability to identify and assimilate external knowledge flows, which has been labelled by Zahra and George [3] as PAC. Although these authors have built the theoretical foundation of PAC - with the notable exception of Jansen et al. [9] - there are no empirical attempts to test their framework. This constitutes the value-added of the present research.

This paper contributes to the literatures on absorptive capacity and innovation management, and offers several insights to practitioners. First, the results point out to the important role played by external linkages in the process of experiential learning that drives the 
accumulation of PAC. This research indicates that firms which are involved in $R \& D$ collaborations and market-based transactions in R\&D develop a stronger ability to understand and assimilate knowledge flows pertaining to the external environment. Second, our findings reveal that experience with knowledge search is a key antecedent of PAC. This has important implications for the process of accumulation of absorptive capacity. More specifically, this research shows that there is a strong path-dependent component in such a process, and firms that have been involved in R\&D-related activities in the past show higher rates of accumulation of this ability [4]. In turn, this implies that heterogeneity in the level of PAC tends to persist across time, making PAC a strong candidate as a source of competitive advantage [5]. Third, our study confirms the crucial role of PAC for innovation. We find that firms with higher levels of such capability systematically obtain larger shares of their sales from new or substantially improved products. Our findings also point out that such effect is stronger when internal information flows are more efficient. This result supports Zahra and George's [3] argument that PAC is a necessary condition for achieving competitive advantage in innovation, but firms also need to develop the ability to transform and exploit external knowledge in order to fully benefit from it. Firms need to possess RAC. Future studies might deepen this analysis by collecting more precise measures of RAC. Finally, this study underlines the crucial role of internal events as stimuli for quickening the accumulation of PAC. We find that firms that undergo profound changes that encompass serious modifications in the design of the organization, strategy and marketing show larger levels of PAC. Hence, an important internal reshaping might serve the purpose of making the firm more outward looking and receptive to external information. A crisis is therefore not necessarily a negative event [14]. It might trigger a change in attitude towards external knowledge $[30,43]$. This might be especially useful for those firms suffering from the so-called "not invented here syndrome" [44].

This study is subject to a number of limitations that might also constitute opportunities for future research. First, we have been forced to be eclectic in the way we measured some of the variables and constructs. Although we have used survey data, we neither have directly developed the questionnaire nor was it structured to answer the research questions we addressed in this paper. In particular we have no sensible measure for the efficiency factor, i.e. the ratio between PAC and
RAC. ${ }^{10}$ As a first approximation we have argued that the importance attributed by our sample firms to internal information exchanges might somehow capture for the presence of socialization and knowledge sharing mechanisms, which the theory associates with the magnitude of the efficiency factor [3]. The questionnaire does not provide a direct measure of PAC either. However, we think that the way we have built our indicator is rather satisfactory, and moreover it is solidly grounded on the extant theory. Hence, we think that this research sheds insights on the antecedents and outcomes of PAC, while the findings concerning the role and importance of RAC must be interpreted with caution. Second, most of the data were self-reported assessments by firm CEOs. Although we hope that the institution that administered the questionnaire (INE) took steps both in the design and testing phases to limit concerns regarding single-informant data, we did not directly supervise this process. We trust the experience and ability of the questionnaire administrator. However, the issues of key informant bias and common method bias cannot be totally ruled out. Third, this research was conducted using a sample of Spanish firms. We do not have any specific reason to believe that nationality might bias the results in a predictable direction. However, only by extending this research to other countries could one prove this conjecture and generalize the findings. Fortunately, this is a very feasible avenue for future research. The very same data set we have used for Spanish firms is available for many other European countries (the socalled "CIS"). This makes it possible to replicate this research using basically the same variables and measures. Finally, the data employed in this study were cross-sectional. It is clear that in order to establish the causal claims of the model one needs longitudinal data. Hence, our results should be interpreted as association among variables and not in terms of causality. This limitation is likely to be solved in the near future. Indeed, a new wave of data (CIS4 database) will soon be available. We believe that having a panel would improve the strength of our findings and would allow us to address new and interesting research questions.

\section{Acknowledgments}

The data set used in this paper was made available to us by INE, the Spanish Institute of Statistics. INE

\footnotetext{
${ }^{10}$ We could eventually collect this information approaching directly a workable subset of our sample firms. For the time being, this channel is however not viable since we are not allowed to know the identity of the firms of our database.
} 
also provided valuable research assistance. We would like to thank Alvaro Escribano, Marco Giarratana, the Editor William King, three anonymous reviewers and seminar participants at the Academy of Management Conference (Honolulu, 2005) and the Strategic Management Society (Orlando, 2005) for comments and suggestions on an earlier draft. Financial support from the Fundación Ramón Areces and from the Comunidad Autónoma de Madrid (project s-0505/tic/000230) is gratefully acknowledged. The usual disclaimer applies.

\section{Appendix A. Correspondence between the CNAE codes and the SIC codes}

\begin{tabular}{lll}
\hline & CNAE & SIC \\
\hline $\begin{array}{l}\text { Extracting, mining } \\
\text { and quarrying of } \\
\text { non-metallic minerals } \\
\text { except fuels }\end{array}$ & $10-14$ & $10-14$ \\
$\begin{array}{l}\text { Manufacturing } \\
\text { industries }\end{array}$ & $15-37$ & $20-39$ \\
$\begin{array}{l}\text { Electricity gas and } \\
\text { water }\end{array}$ & 40,41 & 44,49 \\
$\begin{array}{l}\text { Building } \\
\text { Retail }\end{array}$ & 45 & $15-17$ \\
$\begin{array}{l}\text { Hotels } \\
\text { Transports, storage } \\
\text { and communications }\end{array}$ & $50-52$ & $50-59$ \\
$\begin{array}{l}\text { Financial } \\
\text { intermediation }\end{array}$ & $65-64$ & 70 \\
$\begin{array}{l}\text { Information } \\
\text { technologies }\end{array}$ & $72,42,45-48$ \\
$\begin{array}{l}\text { Research and } \\
\text { development }\end{array}$ & 73 & $60-67$ \\
$\begin{array}{l}\text { Other services } \\
\text { Public services }\end{array}$ & $70,71,74$ & $72-76$ \\
\begin{tabular}{l} 
Entertainment \\
\hline
\end{tabular} & $85,90-99$ & 41,43 \\
\hline
\end{tabular}

\section{Appendix B. Operational measures of some key variables}

$P A C$ : Please indicate the importance (from 1 to 4 ) for your innovation activity of the following external sources of information during the period 1998-2000:

1. suppliers,

2. customers,

3. competitors,

4. universities,

5. public research institutions and technology parks,
6. conferences, meetings and specialized journals,

7. exhibitions and showrooms.

Innovation performance: Please identify the share of 2000 sales due to new products or services introduced in the market during the period 1998-2000.

Contracted $R \& D$ : Did your firm acquire external R\&D during the period 1998-2000? Yes/no.

$R \& D$ collaboration: Did your firm sign $\mathrm{R} \& \mathrm{D}$ cooperation agreements with other firms or institutions during the period 1998-2000? Yes/no.

IATs: Did your firm undertake during the period 1998-2000:

1. A change in strategy? Yes/no.

2. A change in the organization design? Yes/no.

3. A change in marketing practices? Yes/no.

SIMs: Please indicate the importance (from 1 to 4 ) for your innovation activity of the following internal sources of information during the period 1998-2000:

1. departments and employees,

2. other subsidiaries of the same group.

\section{References}

[1] Teece D, Pisano G. The dynamic capabilities of firms: an introduction. Industrial and Corporate Change 1994;3(3): 537-56.

[2] Teece DJ, Pisano G, Shuen A. Dynamic capabilities and strategic management. Strategic Management Journal 1997;18:509-33.

[3] Zahra SA, George G. Absorptive capacity: a review, reconceptualization, and extension. Academy of Management Review 2002;27:185-203.

[4] Cohen W, Levinthal D. Absorptive capacity: a new perspective on learning and innovation. Administrative Science Quarterly 1990;35(1):128-52.

[5] Barney J. Firm resources and sustained competitive advantage. Journal of Management 1991;17:771-92.

[6] Zollo M, Winter S. Deliberate learning and the evolution of dynamic capabilities. Organization Science 2002;13:339-51.

[7] Vekstein D. Managing knowledge and corporate performance: an empirical analysis of the world automobile industry. Omega 1998;26(5):551-68.

[8] Arora A, Gambardella A. Evaluating technological information and utilizing it: scientific knowledge, technological capability, and external linkages in biotechnology. Journal of Economic Behavior and Organization 1994;24:91-114.

[9] Jansen J, Van den Bosch F, Volberda H. Managing potential and realized absorptive capacity: how do organizational antecedents matters?. Academy of Management Journal 2005;48(6): 999-1015.

[10] Cassiman B, Veugelers R. R\&D cooperation and spillovers: some empirical evidence from Belgium. American Economic Review 2002;92(4):1169-84. 
[11] Pennings JM, Harianto F. The diffusion of technological innovation in the commercial banking industry. Strategic Management Journal 1992;13:29-46.

[12] Tsai W. Knowledge transfer in intra-organizational networks: effects of network position and absorptive capacity on business unit innovation and performance. Academy of Management Journal 2001;44:996-1004.

[13] Van den Bosch F, Van Wijk R, Voberda H. Absoptive capacity: antecedents. In: Easterby-Smith M, Lyles MA, editors. Handbook of organizational learning and knowledge management. Oxford: Blackwell Publishing; 2003.

[14] Kim L. Crisis construction and organizational learning: capability building in catching-up at Hyundai Motor. Organization Science 1998;9:506-21.

[15] Granstrand O. The economics and management of intellectual property. Cheltanham, UK: Edward Elgar; 1999.

[16] March JG. Exploration and exploitation in organizational learning. Organization Science 1991;2(1):71-8.

[17] Levinthal D, March JG. The myopia of learning. Strategic Management Journal 1993;14:95-112.

[18] Szulanski G. Exploring internal stickiness: impediments to the transfer of best practice within the firm. Strategic Management Journal 1996;17:27-43.

[19] Rosenkopf L, Nerkar A. Beyond local search: boundary spanning, exploration and impact in the optical disk industry. Strategic Management Journal 2001;22:287-306.

[20] Spender JC. Making knowledge the basis of a dynamic theory of the firm. Strategic Management Journal 1996;17:45-62.

[21] George G, Zahra SA, Wood D. The effects of business-university alliances on the innovative output and financial performance: a study of publicly traded biotechnology companies. Journal of Business Venturing 2002;17(6):577-608.

[22] George G. Learning to be capable: patenting and licensing at the Wisconsin alumni research foundation 1925-2002. Industrial and Corporate Change 2005;14:119-51.

[23] Nelson R, Winter W. An evolutionary theory of economic change. Cambridge, MA: Harvard University Press; 1982.

[24] Ahuja G, Katila R. Technological acquisitions and the innovation performance of acquiring firms: a longitudinal study. Strategic Management Journal 2001;22(3):197-220.

[25] Kumar R, Nti K. Differential learning and interaction in alliance dynamics: a process and outcome discrepancy model. Organization Science 1998;9(3):356-67.

[26] Van Wijk R, Van den Bosch F, Voberda H. The impact of knowledge depth and breadth of absorbed knowledge on levels of exploration and exploitation. Paper presented at the annual meeting of the Academy of Management, Washington, DC; 2001 .

[27] Dean JW, Sharfman MP. Procedural rationality in the strategic decision making process. Journal of Management Studies 1993;30:607-30.
[28] Maritan CA. Capital investment as investing in organizational capabilities: an empirically grounded process model. Academy of Management Journal 2001;44(3):513-31.

[29] Cyert R, March J. A behavioral theory of the firm. Englewood Cliffs, NJ: Prentice-Hall; 1963.

[30] Winter S. The satisficing principle in capability learning. Strategic Management Journal 2000;21:981-96.

[31] Jaffe A, Trajtenberg M, Henderson R. Geographic localization of knowledge spillovers as evidenced by patent citation. Quarterly Journal of Economics 1993;108(3):577-98.

[32] Podsakoff PM, MacKenzie SB, Lee J. Common method biases in behavioral research: a critical review of the literature and recommended remedies. Journal of Applied Psychology 2003;88(5):879-903.

[33] Cassiman B, Veugelers R. In search of complementarity in the innovation strategy: internal $\mathrm{R} \& \mathrm{D}$ and external knowledge acquisition.. Management Science 2006;52(1):68-82.

[34] He ZL, Wong PK. Exploration vs. exploitation: an empirical test of the ambidexterity hypothesis. Organization Science 2004;15(4):481-94.

[35] Hagedoorn J, Cloodt M. Measuring innovative performance: is there an advantage in using multiple indicators?. Research Policy 2003;32:1365-79.

[36] Henderson R, Cockburn I. Measuring competence? Exploring firm effects in pharmaceutical research. Strategic Management Journal 1994;15:63-84.

[37] Arrow K. Economic welfare and the allocation of resources for inventions. In: Nelson R, editor. The rate and direction of inventive activity. Princeton, NJ: Princeton University Press; 1962.

[38] Acs Z, Audretsch D. Innovation in large and small firms: an empirical analysis. American Economic Review 1988;78: 678-90.

[39] Henderson R. Underinvestment and incompetence as responses to radical innovation: evidence from the semiconductor photolithographic alignment equipment industry. Rand Journal of Economics 1993;24(2):248-70.

[40] Christensen C. The innovator's dilemma. Cambridge, MA: Harvard Business School Press; 1997.

[41] Cohen W, Levinthal D. Innovation and learning: the two faces of R\&D. Economic Journal 1989;99:569-96.

[42] Kline RB. Principles and practice of structural equation modeling. New York: The Guilford Press; 1998.

[43] Huber G. Organizational learning: the contributing processes and the literature. Organization Science 1991;2:88-115.

[44] Allen TJ, Katz R. Investigating the not-invented-here (NIH) syndrome: a look at the performance, tenure, and communications patterns of $50 \mathrm{R} \& \mathrm{D}$ project groups. R\&D Management 1982;12(1):7-19. 